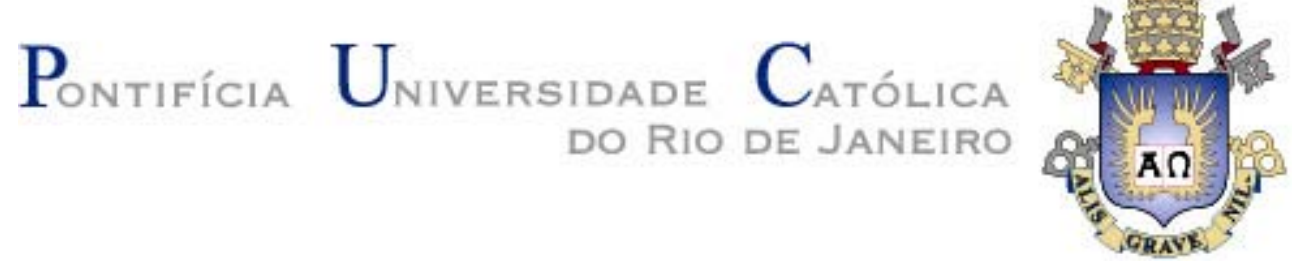

Sylvia Therezinha de Almeida Moraes

A trajetória internacional de uma empresa brasileira líder no setor de software: um estudo sobre a Totvs

Dissertação de Mestrado

Dissertação apresentada ao Programa de Pósgraduação em Administração de Empresas da PUCRio como requisito parcial para a obtenção do titulo de Mestre em Administração de Empresas.

Orientadora: Profa. Angela Maria Cavalcanti da Rocha 
Sylvia Therezinha de Almeida Moraes

\title{
A trajetória internacional de uma empresa brasileira líder no setor de software: um estudo sobre a Totvs
}

Dissertação apresentada como requisito parcial para obtenção do grau de Mestre pelo Programa de Pósgraduação em Administração de Empresas da PUC-Rio. Aprovada pela Comissão Examinadora abaixo assinada.

\author{
Prof $^{a}$. Angela Maria Cavalcanti da Rocha \\ Orientadora \\ Departamento de Administração - PUC-Rio
}

Prof. Jorge Manoel Teixeira Carneiro Departamento de Administração - PUC-Rio

Prof. Renato Dourado Cotta de Mello

COPPEAD - UFRJ

Prof ${ }^{a}$. Mônica Herz

Vice-Decana de Pós-Graduação do CCS

Rio de Janeiro, 11 de abril de 2012 
Todos os direitos reservados. É proibida a reprodução total ou parcial do trabalho sem autorização da universidade, da autora e da orientadora.

\section{Sylvia Therezinha de Almeida Moraes}

Graduada em Matemática pela Pontifícia Universidade Católica - RJ em 1979. Trabalhou por 27 anos na área de Tecnologia da Informação nas empresas Vale do Rio Doce, Xerox e EDS.

Ficha Catalográfica

Moraes, Sylvia Therezinha de Almeida

A trajetória internacional de uma empresa brasileira líder no setor de software : um estudo sobre a Totvs / Sylvia Therezinha de Almeida Moraes ; orientadora: Angela Maria Cavalcanti da Rocha. 2012.

93 f. : il. (color.) ; $30 \mathrm{~cm}$

Dissertação (mestrado)-Pontifícia Universidade Católica do Rio de Janeiro, Departamento de Administração, 2012.

Inclui bibliografia

1. Administração - Teses. 2. Indústria de software. 3. Empreendedorismo internacional. 4. Internacionalização. I. Rocha, Angela Maria Cavalcanti. II. Pontifícia Universidade Católica do Rio de Janeiro. Departamento de Administração. III. Título. 
Essa dissertação é dedicada ao meu pai, que sempre foi meu maior incentivador e exemplo de trabalho, responsabilidade e capacidade intelectual. 


\section{Agradecimentos}

Agradeço, em primeiro lugar, à minha orientadora, professora Angela da Rocha, por todo apoio, pelas revisões, pelo tempo que investiu em nossas discussões e principalmente pela confiança depositada na minha capacidade.

Agradeço ao Sr. Wilson de Godoy, vice-presidente da Totvs que me concedeu uma excelente entrevista, cedendo um tempo precioso de seu dia de trabalho. Agradeço também ao Sr. Luiz Olavo Junqueira Dantas, Diretor da Totvs, que intercedeu junto ao Sr. Wilson para me conceder a entrevista e ainda, agradeço ao meu grande amigo e afilhado, Ricardo Castro, por não ter medido esforços para me encaminhar aos membros da diretoria da Totvs.

Agradeço ao CNPq e à FAPERJ pelas bolsas de estudo que me mantiveram nos dois anos de mestrado e ao NUPIN pelo custeio das despesas incorridas para a realização da entrevista.

Agradeço a todos os colegas de mestrado, pela troca de experiências e conhecimento, pelos momentos de estudo e de distração, ao longo dos dois anos de mestrado. Destaco, no entanto, André Giudice, Daniel de Souza, Juliana Werneck, Nelson Dabul, e Melissa Senra, que não só compartilharam os momentos mais intensos de trabalho, como se tornaram amigos para sempre.

Agradeço à minha família, meus filhos e meu marido, que sempre me apoiaram nas minhas decisões de carreira, em especial nesse momento de transição para a área acadêmica. 


\section{Resumo}

Moraes, Sylvia Therezinha de Almeida; Rocha, Angela Maria Cavalcanti da. A trajetória internacional de uma empresa brasileira líder no setor de software: um estudo sobre a Totvs. Rio de Janeiro, 2012. 93p. Dissertação de Mestrado - Departamento de Administração de Empresas, Pontifícia Universidade Católica do Rio de Janeiro.

A indústria de software no Brasil, apesar de considerada prioritária e estratégica nas políticas de incentivo do governo, têm apresentado dificuldades para se firmar no cenário internacional. Entretanto, algumas empresas se sobressaem, gerando interesse tanto do meio acadêmico quanto do empresarial pela evolução do processo de internacionalização dessas firmas. No intuito de investigar esse fato, o presente trabalho teve como escopo analisar a trajetória de internacionalização de uma empresa de software líder no Brasil, sendo selecionada para tal a empresa Totvs. O estudo realiza uma revisão da literatura, apresentando os desenvolvimentos teóricos recentes a respeito de internacionalização de empresas, abrangendo duas teorias de internacionalização: Teoria de Uppsala e a Teoria do Empreendedorismo Internacional. O método escolhido para concretização da pesquisa foi o Estudo de Caso, tendo utilizados dados primários (entrevista) e secundários (livro sobre a empresa, informações da internet, notícias publicadas na imprensa e documentos da empresa). Os resultados indicaram que o sucesso da estratégia de internacionalização da Totvs está primordialmente atrelado a dois fatores: (i) às características empreendedoras de seus dirigentes e (ii) não por acaso, ao rápido movimento estratégico de internacionalização por parte da empresa quando se deparou com mudanças ambientais na economia local (em particular, a abertura do mercado brasileiro à concorrência internacional). O estudo também aponta que, embora a Totvs tenha iniciado o processo de forma pouco estruturada, a empresa soube aprender com os erros e com o passar do tempo criou um processo bem sucedido de escolha de entrada em outros países.

\section{Palavras-chave}

Indústria de software, empreendedorismo internacional, internacionalização. 


\section{Abstract}

Moraes, Sylvia Therezinha de Almeida; Rocha, Angela Maria Cavalcanti da. The international path of a Brazilian leader in the software industry: a study on Totvs. Rio de Janeiro, 2012. 93p. MSc. Dissertation Departamento de Administração de Empresas, Pontifícia Universidade Católica do Rio de Janeiro

The software industry in Brazil, although considered within the priority and strategic government policies to encourage the sector, has presented difficulties to stand in the international arena. However, some companies stand out, creating attention on the process of evolution of internationalization of these firms in both academic and business arenas. In order to investigate this fact, the scope of this study was to analyze the trend of internationalization of a leading software company in Brazil, being selected for such the company Totvs. The study included a literature review, presenting recent theoretical developments concerning the internationalization of companies, including two theories of internationalization: the Uppsala Theory and the Theory of International Entrepreneurship. The method chosen to implement the survey was the case study, having used primary data (interviews) and secondary data (book about the company, information from the Internet, press reports and company documents). The results indicated that the success of the internationalization strategy of Totvs is tied primarily to two factors: (i) the entrepreneurial characteristics of its directors and (ii) not by chance, the rapid strategic movement towards internationalization done by the company when it came across environmental changes in the local economy (in particular, the opening of the market to international competition). The study also points out that although Totvs have started the process in a loosely structured way, the company was able to learn from mistakes and over time have created a successful process of entry choice into other countries.

\section{Keywords}

Software industry, International Enterpreneurship, Internationalization. 


\section{Sumário}

1. Introdução 11

1.1. Objetivos e Relevância do Estudo 13

1.2. Delimitação do Estudo 13

1.3. Organização do Estudo 13

2. Revisão de Literatura 15

2.1. Modelo de Uppsala 16

2.1.1. O Modelo Original 16

2.1.2. O Modelo Revisado 20

2.2. Empreendedorismo Internacional 28

3. Metodologia 44

3.1. O Problema 44

3.2. A Perguntada da Pesquisa 44

3.3. Método da Pesquisa $\quad 45$

3.4. Seleção do Caso 47

3.5. Fontes de Dados 48

3.6. Coleta e Análise de Dados 49

3.7. Limitações do Método 50

4. Estudo de Caso: Totvs 51

4.1. O Setor de Software no Brasil e no Mundo 51

4.2. A Totvs 56

4.2.1. Trajetória da Totvs $\quad 57$

4.2.2. Processo de Internacionalização 66

4.2.2.1. Linha do Tempo 66

4.2.2.2. Estratégia de Internacionalização 68

5. Análise do Caso 72

5.1. A Forma de Internacionalização Escolhida pela Totvs 72

5.2. Contribuições da Teoria de Uppsala à Interpretação do Caso Totvs

5.3. Contribuições da Teoria de Empreendedorismo Internacional à Interpretação do Caso Totvs 76

6. Considerações Finais $\quad 81$

6.1. Conclusões 81

6.2. Sugestões para Pesquisas Futuras 84

7. Referência Bibliográfica 86

Anexo 1 - Roteiro de Entrevistas $\quad 91$ 


\section{Lista de figuras}

Figura 1 - Esquema representando os passos trilhados para empresas que se internacionalizam

Figura 2 - Mecanismo básico de internacionalização no Modelo de Uppsala Original

Figura 3 - O modelo do processo de internacionalização de redes de negócio

Figura 4 - Um modelo simples do Processo Empreendedor: Os

Papéis da Mudança, da Criatividade e da Inovação

Figura 5 - Um modelo simples do Processo Internacionalização

Figura 6 - Modelo de forças que influenciam a velocidade de internacionalização

Figura 7 - Contagem dos tópicos mais frequentes tratados na literatura

Figura 8 - Expansão Internacional das EM MNEs - uma perspectiva de trampolim

Figura 9 - International Expansion, Entrepreneurship and Learning 42

Figura 10 - Modelo das dimensões da cultura empreendedora internacional 


\section{Lista de tabelas}

Tabela 1 - Comparação entre métodos de pesquisa

Tabela 2 - Mercado de software em alguns países selecionados em 2001

Tabela 3 - Receita líquida da Indústria Brasileira de Software e Serviços no mercado externo

Tabela 4 - Perfil so setor de Tecnologia da Informação (2009) em US\$bilhões

Tabela 5 - Aquisições da Totvs

Tabela 6 - Participações no Mercado de ERP por Segmento segundo o tamanho das empresas

Tabela 7 - Linha do Tempo do processo de internacionalização

Tabela 8 - Comparação das questões e resultados

Tabela 9 - Comparação com a Teoria de Uppsala

76

Tabela 10 - Comparação com a Teoria de Empreendedorismo Internacional 